\title{
Effect of Different Nd:YAG Laser Power Outputs on Bond Strength of Resin Cement to Zirconia in Comparison to Sandblasting
}

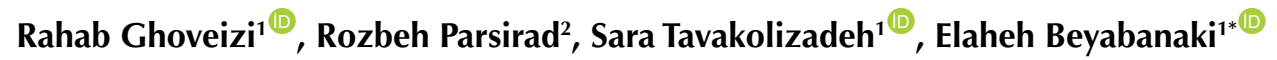 \\ ${ }^{1}$ Assistant Professor, Department of Prosthodontics, School of Dentistry, Shahid Beheshti University of Medical Sciences, \\ Tehran, Iran \\ ${ }^{2}$ Graduate student, Shahid Beheshti University of Medical Sciences, Tehran, Iran
}

\section{*Correspondence to} Elaheh Beyabanaki,

DDS, MS; Assistant Professor Prosthodontics Department, School of Dentistry,

ShahidBeheshti University of Medical Sciences, Tehran, Iran Email: e.beyabanaki@gmail.com

Published online February 16, 2021

\begin{abstract}
Introduction: This study investigated the effect of various laser powers on the shear bond strength (SBS) of resin cement to the zirconia surface.

Methods: Seventy-five zirconia disks were prepared and assigned to five groups including no surface treatment (control group), sandblasting with $50 \mu \mathrm{Al}_{2} \mathrm{O}_{3}$ particles (second group), and $\mathrm{Nd}$ :YAG laser treatments with $2 \mathrm{~W}, 2.5 \mathrm{~W}$ and $3 \mathrm{~W}$ powers respectively (third, fourth and fifth groups). Afterwards, composite resin cylinders were cemented on zirconia disks using dual-curing resin cement. Before thermocycling $\left(2000\right.$ cycles, $\left.5-55^{\circ} \mathrm{C}\right)$, all samples were placed in distilled water at $37^{\circ} \mathrm{C}$ for 24 hours. Using a universal testing machine at the crosshead speed of $0.5 \mathrm{~mm} / \mathrm{min}$, the SBS was examined. Also, using a stereomicroscope, the failure type was determined. Data analyses were performed using Welch and Games-Howell tests $(P<0.05)$.

Results: The mean bond strength difference between the control group and the other groups was significant. The respective bond strength from the highest to the lowest was observed in the sandblast group, the laser group with $2.5 \mathrm{~W}$ power, the laser group with $3 \mathrm{~W}$ power, the laser group with $2 \mathrm{~W}$ power, and finally the control group. However, no significant difference was observed between different laser groups $(P<0.05)$. Also, there was no significant difference between the sandblast and laser groups with $2.5 \mathrm{~W}$ and $3 \mathrm{~W}$ power $(P<0.05)$. Most of the failures in the sandblasting and laser groups with powers of $2.5 \mathrm{~W}$ and $3 \mathrm{~W}$ were mixed, but in the control and $2 \mathrm{~W}$ laser groups, most of the failures were of adhesive nature. Conclusion: The highest bond strength was achieved by sandblasting with $\mathrm{Al}_{2} \mathrm{O}_{3}$ particles and then using an $\mathrm{Nd}$ : YAG laser with a power of $2.5 \mathrm{~W}$.

Keywords: Zirconia ceramic; Air abrasion; Nd: YAG laser; Shear bond strength.
\end{abstract}

\section{Introduction}

Zirconia-based ceramic restorations have gained considerable popularity due to their high aesthetics, biocompatibility and compressive strength, in addition to having similar thermal expansion coefficient as teeth. However, the main drawback to zirconia restoration as compared to glass-ceramic restorations is the weak bonding quality of zirconia to resin cements. ${ }^{1-5}$ This is mainly because of the inability of etching of zirconia structure due to lack of glass and also silica phases that justify using adhesive and silane containing resin cements. ${ }^{1-8}$

Using resin cements containing monomeric phosphate (MDP) to cement ceramic restorations and zirconia bases has been highly advised in this regard. ${ }^{9}$ Furthermore, different methods have been suggested for surface preparation of zirconia restorations. Sandblasting with aluminum oxide particles is one of the methods which increases the bonding surface and increases surface roughness on the ceramic surface, surface energy and surface moisture. ${ }^{10-14}$ In this method, high-speed aluminum particles remove weak ceramic phases and create superficial disorientations. The creation of such disruptions will increase the surface and strengthen the bond. Another method in this regard is the use of silica coating, which increases the bond strength of resin cement to the ceramic.

Laser irradiation also causes abrasion, and microscopic and macroscopic porosities on the ceramic surfaces, which improves the micromechanical adhesion of the resin cement. ${ }^{15-18}$ Different lasers such as Er:YAG, $\mathrm{CO}_{2}$ and Nd:YAG have been used to prepare ceramic surfaces, and different results including higher, lower or similar bond strength results compared to control and also 
sandblasting samples have been reported. ${ }^{19-25}$ During surface preparation by the laser, however, the mechanical properties of the ceramic can change under the influence of temperature change caused by the laser.

The Nd:YAG laser has been used in numerous studies as a method for changing the surface of ceramic before bonding. ${ }^{4,6,23,26-36}$ This laser has been suggested as an effective method for surface roughening and wettability before bonding., ${ }^{3,23,24,34}$ Various power settings and irradiation time of the Nd:YAG laser have been used for zirconia by Liu et al. ${ }^{23}$ This study aimed to investigate the comparative shear bond strength (SBS) of resin cement to ceramic surfaces prepared with different ND:YAG laser powers and sandblasting.

\section{Materials and Methods}

Seventy-five disk samples of multilayer zirconia (KATANA Zirconia ML, Kuraray Noritake Dental Inc., Aichi, Japan) were made with $10 \mathrm{~mm}$ in diameter and 3 $\mathrm{mm}$ in thickness using CAD/ CAM (Amman Girrbach, Ceramill motion 2, Koblach, Austria). All samples were then polished with a silicon carbide paper (600grit matador 991A soflex starcke $\mathrm{GmbH} \&$ Co., Melle, Germany). Then, they were mounted into acrylic molds (Acropars, Tehran, Iran) with dimensions of $4.5 \mathrm{~cm} \times 2$ $\mathrm{cm} \times 1 \mathrm{~cm}$, so that the surface interface of the specimens was level with the acrylic blocks.

The specimens were then distributed into 5 groups as follows: In the first group, no surface treatment was performed on the zirconia samples (control group). In the second group, the sample surfaces were sandblasted using $50 \mu \mathrm{Al}_{2} \mathrm{O}_{3}$ particles with 3 bar pressure, for 40 seconds at a $10 \mathrm{~mm}$ distance. In the third group, the surface of the specimens was prepared by laser Nd:YAG (LightWalker ATS, Fotona, Ljublijana, Slovenia). Specifications of the laser were wavelength: $\lambda=1064 \mathrm{~nm}$ - radiation power $2 \mathrm{~W}$ - frequency of radiation $20 \mathrm{~Hz}$ - time 45 seconds - energy $100 \mathrm{~mJ}$ - pulse waveform radiation and pulse duration of 300 microseconds. In the fourth group, the surfaces of the samples were prepared by the Nd:YAG laser with similar characteristics to group 3, except for the power of $2.5 \mathrm{~W}$ and $125 \mathrm{~mJ}$ energy. Finally, in the fifth group, the surfaces of the samples were also prepared by the Nd:YAG laser with similar characteristics to group 4, except for using the power of $3 \mathrm{~W}$ and $150 \mathrm{~mJ}$ energy. The tip of the optical fiber was placed by hand and at a distance of 1 $\mathrm{mm}$ from the ceramic surface and perpendicular to it. ${ }^{17,23}$ The surface of the samples was then irradiated by a laser without any cooling system.

After surface preparation, the samples were cleaned ultrasonically (Elmasonic-S60H, Elma, Singen/Htw, Germany) with $96 \%$ isopropanol alcohol for 3 minutes. ${ }^{14,23}$ Furthermore, one sample from each group was examined with an electron microscope (SEM Quanta 200, FEI, USA) with a magnification of $\times 5000$ (Figure 1). Then, to check the SBS, the samples were prepared as follows:

Transparent plastic tubes with $3 \mathrm{~mm}$ in diameter and $4 \mathrm{~mm}$ in height were filled with composite resin (Filtek Z250, 3M ESPE, St. Paul, MN, USA) with color A3.5 and then light-cured (Helioulux DLX, Ivoclar Vivadent, Schaan, Liechtenstein) with an intensity of $600 \mathrm{~mW} / \mathrm{cm}^{2}$ for 40 seconds from two directions.

For bonding composites to the surface of zirconia discs, dual-cure resin cements (Panavia F2.0, Kuraray, Okayama, Japan) were used. The surface of zirconia samples and composite cylinders were cleaned using $37 \%$ phosphoric acid for 5 seconds and then rinsed thoroughly. Ceramic primer (Clearfil Ceramic Primer Plus, Kuraray, Okayama, Japan) was used on the dry ceramic surfaces according to the manufacturer's instruction. Also, ED Primer II

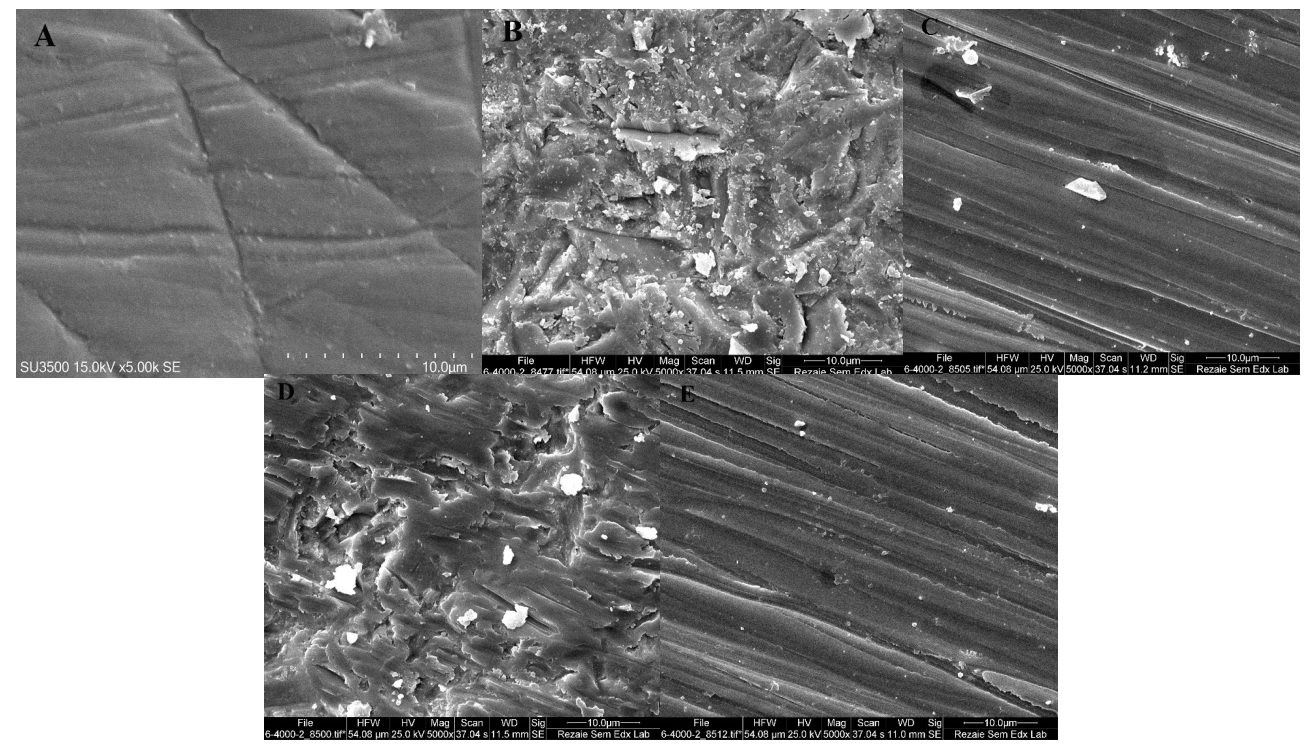

Figure 1. SEM Images of Zirconia Surfaces Prepared by (A) Control, (B) Sandblast, (C) 2 W Nd:YAG, (D) 2.5 W Nd:YAG and (E) 3 W $\mathrm{Nd}$ :YAG. 
(Panavia F2.0, Kuraray, Okayama, Japan) was applied to the composite surface. ${ }^{17,24}$ Then, the resin cements were mixed and placed on the zirconia discs. Resin composite tubes were pressed to the surface of the zirconia samples under a Gillmore needle with a weight of $435.6 \mathrm{~g}$. After 10 seconds of primary curing, the remains of the cement were eliminated and the Oxyguard II gel (Panavia F2.0, Kuraray, Okayama, Japan) was used. Then the final curing was performed in 4 directions each for 40 seconds. All the samples were stored in distilled water at $37^{\circ} \mathrm{C}$ for 24 hours and then put under 2000 cycles $^{14}$ of heat between $5^{\circ} \mathrm{C}$ and $55^{\circ} \mathrm{C}$ with 20 seconds of exposure per bath and a 10 -second transmission time.

After thermocycling, the samples were placed at room temperature for an hour and then they were tested for the SBS by a universal testing machine (Bongshin, DBBP-2t, Seongnam, Korea) at a speedhead of $0.5 \mathrm{~mm} /$ min (Figure 2). The broken surfaces were observed under a stereomicroscope (Carl Zeiss, Germany) with a magnification of $\times 40$ to determine the type of failure (adhesive or mixed) after the shear bond test.

SPSS version 24 was used to analyze the data. Normal distribution of data was verified and validated using the Kolmogorov-Smirnov test. Welch and Games-Howell analyses were used to analyze the SBSs between groups. The analysis for comparing the type of failure between groups was performed using the chi-square test. All the tests were executed at the significance level of 0.05 .

\section{Results}

The SBS (mean \pm standard deviation) is shown in Table 1. The mean bond strength between the groups was compared using Welch analysis. The results indicated that the bond strengths significantly varied between groups $(P$ $=0.007$ ).

According to Games-Howell analysis, the difference between the sandblast group and the $2 \mathrm{~W}$ laser groups was significant $(P=0.012)$, and the SBS of the sandblast group was more than the laser group (Table 2). Furthermore, the control group revealed significantly different SBSs from the other groups $(P<0.001)$ and showed less SBS as compared to the sandblast and laser groups. However, no significant difference was found between the sandblast and $2.5 \mathrm{~W}$ and $3 \mathrm{~W}$ groups $(P=0.254$ and $P=0.069)$. Also, the three laser groups had no significant difference $(P>0.05)$.

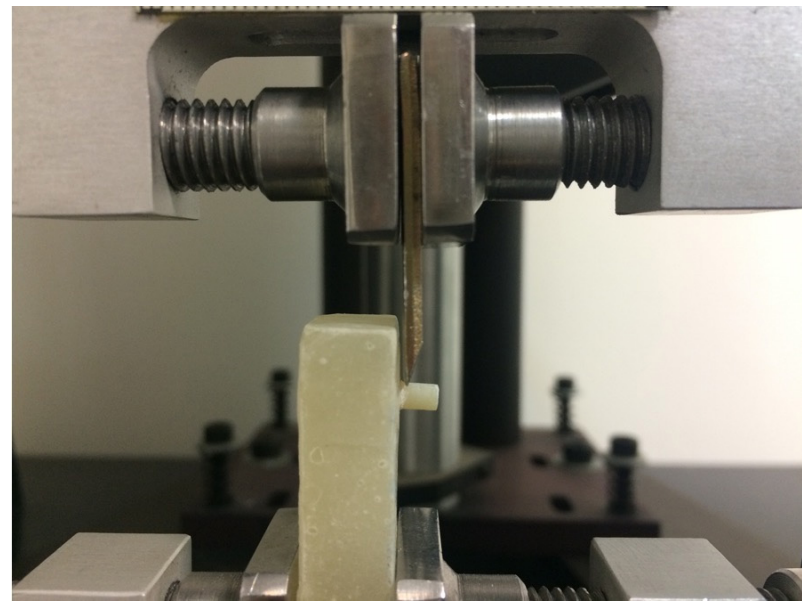

Figure 2. Evaluating the Shear Bond Strength Using the Universal Testing Machine.

Furthermore, according to SEM, the failure mode in the sandblast and $2.5 \mathrm{~W}$ and $3 \mathrm{~W}$ laser groups was of a mixed entity. However, in the control and $2 \mathrm{~W}$ groups, the adhesive fracture was dominant.

\section{Discussion}

This study evaluated the influence of various surface preparation methods of the zirconia ceramic on its SBS to resin cement. The null hypothesis was that there is no difference in the SBS of resin cement to zirconia disks prepared by different laser powers as compared to sandblasting.

One of the major factors in the bonding of zirconia restorations to resin-based cements is their surface roughness. ${ }^{4}$ Therefore, different methods have been employed to create this roughness, including sandblasting and laser treatments. Previous studies have investigated different laser parameters. In a systematic review by García-Sanz et al, ${ }^{15}$ it was shown that generally ND:YAG laser treatment significantly increases the bond strength of resin cements to zirconia as compared to no treatment. According to the results of the current study, the characteristics of the zirconia surface evidently changed after various surface preparations. According to SEM, the sandblast surface treatment also caused the highest level of surface roughness, which is in accordance with Ersu and colleagues' study. ${ }^{5}$ According to Zanatta et al ${ }^{18}$ the mean $\mathrm{Ra}$ values (surface roughness) for the laser

Table 1. The Shear Bond Strength (Mean \pm Standard Deviation) of Groups With Different Surface Treatments

\begin{tabular}{|c|c|c|c|c|c|}
\hline Group & Mean & Std. Deviation & Std. Error & Minimum & Maximum \\
\hline Sandblast & 13.2114 & 2.87379 & 0.76805 & 8.17 & 17.80 \\
\hline control & 3.7987 & .97953 & 0.26179 & 2.36 & 6.38 \\
\hline Nd: YAG laser $(2.0 \mathrm{~W})$ & 9.6207 & 2.43111 & 0.64974 & 4.43 & 14.67 \\
\hline Nd: YAG laser $(2.5 \mathrm{~W})$ & 10.8786 & 3.02969 & 0.80972 & 7.30 & 17.40 \\
\hline Nd: YAG laser $(3.0 \mathrm{~W})$ & 10.3836 & 2.48605 & 0.66443 & 6.96 & 16.40 \\
\hline
\end{tabular}


Table 2. Pairwise Comparison of Different Surface Treatment Methods

\begin{tabular}{|c|c|c|c|c|c|}
\hline \multirow{2}{*}{ Treatment Type } & \multirow{2}{*}{ Treatment Type } & \multirow{2}{*}{ Mean Difference } & \multirow{2}{*}{$P$ Value } & \multicolumn{2}{|c|}{ 95\% Confidence Interval } \\
\hline & & & & Lower Bound & Upper Bound \\
\hline \multirow{4}{*}{ Sandblast } & Control & $9.41277^{*}$ & 0.000 & 6.9264 & 11.8991 \\
\hline & $2.0 \mathrm{~W}$ & $3.59071^{*}$ & 0.012 & 0.6388 & 6.5426 \\
\hline & $2.5 \mathrm{~W}$ & 2.33286 & 0.254 & -0.9361 & 5.6018 \\
\hline & $3.0 \mathrm{~W}$ & 2.82786 & 0.069 & -0.1506 & 5.8063 \\
\hline \multirow{4}{*}{ Control } & Sandblast & $-9.41277^{*}$ & 0.000 & -11.8991 & -6.9264 \\
\hline & $2.0 \mathrm{~W}$ & $-5.82205^{*}$ & 0.000 & -7.9517 & -3.6924 \\
\hline & $2.5 \mathrm{~W}$ & $-7.07991^{*}$ & 0.000 & -9.6932 & -4.4666 \\
\hline & $3.0 \mathrm{~W}$ & $-6.58491^{*}$ & 0.000 & -8.7585 & -4.4113 \\
\hline \multirow{4}{*}{$\mathrm{Nd}$ : YAG laser $(2.0 \mathrm{~W})$} & Sandblast & $-3.59071^{*}$ & 0.012 & -6.5426 & -0.6388 \\
\hline & control & $5.82205^{*}$ & 0.000 & 3.6924 & 7.9517 \\
\hline & $2.5 \mathrm{~W}$ & -1.25786 & 0.745 & -4.3084 & 1.7926 \\
\hline & $3.0 \mathrm{~W}$ & -0.76286 & 0.922 & -3.4844 & 1.9587 \\
\hline \multirow{4}{*}{ Nd: YAG laser (2.5 W) } & Sandblast & -2.33286 & 0.254 & -5.6018 & 0.9361 \\
\hline & control & $7.07991^{*}$ & 0.000 & 4.4666 & 9.6932 \\
\hline & $2.0 \mathrm{~W}$ & 1.25786 & 0.745 & -1.7926 & 4.3084 \\
\hline & $3.0 \mathrm{~W}$ & 0.49500 & 0.989 & -2.5807 & 3.5707 \\
\hline \multirow{4}{*}{ Nd: YAG laser $(3.0 \mathrm{~W})$} & Sandblast & -2.82786 & 0.069 & -5.8063 & 0.1506 \\
\hline & control & $6.58491^{*}$ & 0.000 & 4.4113 & 8.7585 \\
\hline & $2.0 \mathrm{~W}$ & 0.76286 & 0.922 & -1.9587 & 3.4844 \\
\hline & $2.5 \mathrm{~W}$ & -0.49500 & 0.989 & -3.5707 & 2.5807 \\
\hline
\end{tabular}

group were approximately 5 times higher than other preparations, contrary to the visual parameters shown by the SEM microscope. However, Ra measured in their study was defined as the difference in height between the valleys and the peaks at the surface, while preparation with sandblasting created more peaks, which explains the positive relationship between surface roughness and bond strength. ${ }^{18}$

SEM results clearly showed that laser irradiation could change the outer surface of the zirconia ceramic. The smooth surface with disordered micro-cracks on the ceramic surface resulted from Nd:YAG laser irradiation. This finding is in accordance with previous studies that reported the development of micro-cracks in the zirconia after laser preparations with Nd: YAG. ${ }^{3,18}$ Since the level of surface pigment and water content affect the energy absorbed by laser radiation, ${ }^{21}$ the opaque color and waterfree nature of zirconia samples could have affected the results. The Nd:YAG laser causes bubbles and blisters as a result of the micro explosion, evaporation and also melting of the surface. ${ }^{22}$ According to the results of the SEM, the samples prepared by the $2 \mathrm{~W}$ laser showed some micro-cracks. However, using the $2.5 \mathrm{~W}$ laser mostly resulted in creating bubbles and blisters surrounded by a porous layer. On the other hand, the $3 \mathrm{~W}$ laser increased the micro-cracks and also decreased the blister formation.

The results also showed that the highest to lowest
SBSs were seen in the sandblasting group using $50 \mu \mathrm{m}$ aluminum oxide particles (13.21 $\mathrm{MPa})$, the Nd: YAG laser with a power of $2.5 \mathrm{~W}$ group (10.94 MPa), the laser with a power of $3 \mathrm{~W}$ group $(10.38 \mathrm{MPa})$, and the laser with a power of $2 \mathrm{~W}$ group $(9.69 \mathrm{MPa})$ respectively. Although the difference between SBS in laser groups was not significant, the lower bond strength seen in the $2 \mathrm{~W}$ group as compared to $2.5 \mathrm{~W}$ could be due to fewer surface changes caused by the lower heat created by this laser power.

On the other hand, the creation of heat induced a damaged layer on the surface of samples treated with a high-power output as $3 \mathrm{~W}$ could explain the lower bond strength observed in this group in comparison to the 2.5 W group. This damaged layer containing micro-cracks, as explained previously, might be weakly attached to the outer substrate layer, and due to insufficient bond strength to the specimen, it could have been broken after applying slight force. ${ }^{35}$ The irradiation distance and also using a cooling system during irradiation could have affected this finding. ${ }^{17}$ The results of other studies also showed higher SBS using the sandblasting method as compared to laser radiation. ${ }^{23,26}$ However, Liu et $\mathrm{al}^{23}$ reported lower SBS for 2 $\mathrm{W}$ and $3 \mathrm{~W}$ lasers that might have been due to the higher thermal cycles used in their studies (20000 cycles). On the other hand, the result of our study was in contrast to some other studies that found lower SBS for the sandblasting 
method as compared to the laser group., ${ }^{4,25}$ It can be due to the higher laser energy and duration used in Usumez and colleagues' study, ${ }^{4}$ which could simultaneously decrease the zirconia toughness due to phase transformation from tetragonal to monoclininc. ${ }^{4}$ Also, the resin cement used in the current study was different from the cement used in Usumez and colleagues' study, ${ }^{4}$ which might have affected the results. Higher bond strengths after Nd:YAG laser irradiation to zirconia containing ceramics as compared to sandblasting have also been reported by other studies. ${ }^{34,35}$

Furthermore, differences observed in the results of various studies could be due to the different parameters used in laser irradiation, different types of zirconia ceramic and cement, the storage time of the samples in distilled water, using graphite powder to increase the laser energy absorption, and finally, the number of cycles used during the thermocycling process. ${ }^{4,23,33-35}$ On the other hand, the laser parameters such as the laser type and the energy level used in most studies were not consistent and varied from 100 to $200 \mathrm{~mJ}$, making it difficult to compare the studies. ${ }^{4,16}$

The bond failure mode is another parameter to analyze the bond strength quality and effectiveness. For the groups prepared by airborne particles and Nd:YAG lasers with powers of $2.5 \mathrm{~W}$ and $3 \mathrm{~W}$, most bond failures were of mixed type. However, the failure mode in other groups was of adhesive nature, which also indicated the lower bond strength resulting in a fracture in the interface between resin and zirconia. Considering the results of SBS, surface roughness and failure mode simultaneously, using air abrasion and the laser with a power of 2.5 could be recommended for pre-bonding surface treatments. However, since this study was conducted in vitro, the results should be interpreted with caution and clinical studies are recommended to confirm these findings. A limitation of the current study was the lack of cyclic loading to evaluate the permanency of bond strength of the surfaces treated with various surface treatment methods.

\section{Conclusion}

According to the findings of this study, the subsequent results were obtained:

1. Nd:YAG laser radiation and sandblasting changed the morphological characteristics of zirconia and roughened its surface.

2. Using Nd:YAG laser irradiation with different powers created less SBS as compared to sandblasting.

3. Increasing the laser power from 2 to $2.5 \mathrm{~W}$ increased the surface roughness and the SBS.

\section{Ethical Considerations}

Not applicable.

\section{Conflict of interests}

None.

\section{Funding}

None.

\section{References}

1. Anusavice KJ, Shen C, Rawls HR. Phillips' science of dental material. 12th ed. Philadelphia: Elsevier Health Sciences; 2013.

2. Atsu SS, Kilicarslan MA, Kucukesmen HC, Aka PS. Effect of zirconium-oxide ceramic surface treatments on the bond strength to adhesive resin. J Prosthet Dent. 2006;95(6):4306. doi: 10.1016/j.prosdent.2006.03.016.

3. Paranhos MPG, Burnett Jr LH, Magne P. Effect of Nd:YAG laser and $\mathrm{CO} 2$ laser treatment on the resin bond strength to zirconia ceramic. Quintessence Int. 2011;42(1):79-89.

4. Usumez A, Hamdemirci N, Koroglu BY, Simsek I, Parlar $\mathrm{O}$, Sari T. Bond strength of resin cement to zirconia ceramic with different surface treatments. Lasers Med Sci. 2013;28(1):259-66. doi: 10.1007/s10103-012-1136-x.

5. Ersu B, Yuzugullu B, Ruya Yazici A, Canay S. Surface roughness and bond strengths of glass-infiltrated aluminaceramics prepared using various surface treatments. J Dent. 2009;37(11):848-56. doi: 10.1016/j.jdent.2009.06.017.

6. Yenisey M, Dede DO, Rona N. Effect of surface treatments on the bond strength between resin cement and differently sintered zirconium-oxide ceramics. J Prosthodont Res. 2016;60(1):36-46. doi: 10.1016/j.jpor.2015.09.001.

7. Denry I, Kelly JR. State of the art of zirconia for dental applications. Dent Mater. 2008;24(3):299-307. doi: 10.1016/j.dental.2007.05.007.

8. Blatz MB, Sadan A, Martin J, Lang B. In vitro evaluation of shear bond strengths of resin to densely-sintered highpurity zirconium-oxide ceramic after long-term storage and thermal cycling. J Prosthet Dent. 2004;91(4):356-62. doi: 10.1016/j.prosdent.2004.02.001.

9. Madani AS, Astaneh PA, Shahabi S, Nakhaei MR, Bagheri HG, Chiniforush N. Influence of different power outputs of intraoral Nd:YAG laser on shear bond strength of a resin cement to nickel-chromium dental alloy. Lasers Med Sci. 2013;28(1):229-34. doi: 10.1007/s10103-012-1095-2.

10. Burke FJ, Fleming GJ, Nathanson D, Marquis PM. Are adhesive technologies needed to support ceramics? An assessment of the current evidence. J Adhes Dent. 2002;4(1):7-22.

11. Lüthy $\mathrm{H}$, Loeffel $\mathrm{O}$, Hammerle $\mathrm{CH}$. Effect of thermocycling on bond strength of luting cements to zirconia ceramic. Dent Mater. 2006;22(2):195-200. doi: 10.1016/j. dental.2005.04.016.

12. Yoshida K, Tsuo Y, Atsuta M. Bonding of dual-cured resin cement to zirconia ceramic using phosphate acid ester monomer and zirconate coupler. J Biomed Mater Res B Appl Biomater. 2006;77(1):28-33. doi: 10.1002/jbm.b.30424.

13. Wolfart M, Lehmann F, Wolfart S, Kern M. Durability of the resin bond strength to zirconia ceramic after using different surface conditioning methods. Dent Mater. 2007;23(1):45-50. doi: 10.1016/j.dental.2005.11.040.

14. Raeisosadat F, Ghoveizi R, Eskandarion S, Beyabanaki E, Tavakolizadeh S. Influence of different surface treatments on the shear bond strength of resin cement to base metal alloy. J Lasers Med Sci. 2020;11(1):45-49. doi: 10.15171/ jlms.2020.08. 
15. García-Sanz V, Paredes-Gallardo V, Mendoza-Yero O, Carbonell-Leal M, Albaladejo A, Montiel-Company JM, et al. The effects of lasers on bond strength to ceramic materials: A systematic review and meta-analysis. PLoS One. 2018;13(1): e0190736. doi: 10.1371/journal. pone.0190736.

16. Ural Ç, Külünk T, Külünk Ş, Kurt M. The effect of laser treatment on bonding between zirconia ceramic surface and resin cement. Acta Odontol Scand. 2010;68(6):354-9. doi: 10.3109/00016357.2010.514720.

17. Ranjbar Omidi B, Karimi Yeganeh P, Oveisi S, Farahmandpour N, Nouri F. Comparison of micro-shear bond strength of resin cement to zirconia with different surface treatments using Universal adhesive and zirconia primer. J Lasers Med Sci. 2018;9(3):200-6. doi: 10.15171/ jlms.2018.36.

18. Zanatta RF, Esper MÂLR, Pucci CR, Borges AB, Torres CRG. Effects of different surface treatments of zirconia on the bond strength of self-adhesive resinous cement. J Adhes Sci Technol. 2017;31(1):21-30. doi: 10.1080/01694243.2016.1197085.

19. Joukhadar C, Osman E, Rayyan M, Shrebaty M. Comparison between different surface treatment methods on shear bond strength of zirconia (in vitro study). J Clin Exp Dent. 2020;12(3): e264-e70. doi:10.4317/jced.56242.

20. Tanis MC, Akcaboy C. Effects of different surface treatment methods and MDP monomer on resin cementation of zirconia ceramics an in vitro study. J Lasers Med Sci. 2015;6(4):174-81. doi: 10.15171/jlms.2015.15.

21. Coluzzi DJ. Fundamentals of dental lasers: science and instruments. Dent Clin North Am. 2004;48(4):751-70. doi: 10.1016/j.cden.2004.05.003.

22. Marimoto AK, Cunha LA, Yui KC, Huhtala MF, Barcellos DC, Prakki A, et al. Influence of Nd:YAG laser on the bond strength of self-etching and conventional adhesive systems to dental hard tissues. Oper Dent. 2013;38(4):447-55. doi: 10.2341/11-383-L.

23. Liu L, Liu S, Song X, Zhu Q, Zhang W. Effect of Nd: YAG laser irradiation on surface properties and bond strength of zirconia ceramics. Lasers Med Sci. 2015;30(2):627-34. doi: 10.1007/s10103-013-1381-7.

24. Kasraei S, Rezaei-Soufi L, Yarmohamadi E, Shabani A. Effect of $\mathrm{CO}_{2}$ and Nd:YAG lasers on shear bond strength of resin cement to zirconia ceramic. J Dent (Tehran). 2015; 12(9):686-94.

25. Obata A, Tsumura T, Niwa K, Ashizawa Y, Deguchi T, Ito M. Super pulse $\mathrm{CO}_{2}$ laser for bracket bonding and debonding. Eur J Orthod. 1999;21(2):193-8. doi: 10.1093/ejo/21.2.193.

26. Akyıl MŞ, Uzun İH, Bayındır F. Bond strength of resin cement to yttrium-stabilized tetragonal zirconia ceramic treated with air abrasion, silica coating, and laser irradiation. Photomed Laser Surg. 2010;28(6):801-8. doi: 10.1089/pho.2009.2697.

27. Kirmali O, Barutcigil C, Ozarslan MM, Barutcigil K, Harorlı OT. Repair bond strength of composite resin to sandblasted and laser irradiated Y-TZP ceramic surfaces. Scanning. 2015;37(3):186-92. doi: 10.1002/sca.21197.

28. Akin GE, Kaval ME, Turk T, Akin H. Surface roughness and bond strength of zirconia posts to a resin cement after various surface pretreatments. Photomed Laser Surg. 2015;33(5):246-51. doi: 10.1089/pho.2014.3861.

29. Kara O, Kara HB, Tobi ES, Ozturk AN, Kilic HS. Effect of various lasers on the bond strength of two zirconia ceramics. Photomed Laser Surg. 2015; 33(2):69-76. doi: 10.1089/pho.2014.3841.

30. Yavuz T, Özyılmaz ÖY, Dilber E, Tobi ES, Kiliç HŞ. Effect of different surface treatments on porcelain-resin bond strength. J Prosthodont. 2017;26(5):446-54. doi: 10.1111/ jopr.12387.

31. Arami S, Hasani Tabatabaei M, Namdar F, Safavi N, Chiniforush N. Shear bond strength of the repair composite resin to zirconia ceramic by different surface treatment. $J$ Lasers Med Sci. 2014;5(4):171-5.

32. Akyıl MŞ, Yılmaz A, Bayındır F, Duymuş ZY. Microtensile bond strength of resin cement to a feldspathic ceramic. Photomed Laser Surg. 2011;29(3):197-203. doi: 10.1089/ pho.2009.2746.

33. 33: Subaşı MG, İnan Ö. Evaluation of the topographical surface changes and roughness of zirconia after different surface treatments. Lasers Med Sci. 2012;27(4):735-42. doi: 10.1007/s10103-011-0965-3.

34. da Silveira BL, Paglia A, Burnett LH, Shinkai RS, Eduardo $\mathrm{CP}$, Spohr AM. Micro-tensile bond strength between a resin cement and an aluminous ceramic treated with Nd:YAG laser, Rocatec System, or aluminum oxide sandblasting. Photomed Laser Surg. 2005;23(6):543-8. doi: 10.1089/ pho.2005.23.543.

35. Spohr AM, Borges GA, Júnior LH, Mota EG, Oshima HM. Surface modification of In-Ceram Zirconia ceramic by Nd:YAG laser, Rocatec system, or aluminum oxide sandblasting and its bond strength to a resin cement. Photomed Laser Surg. 2008;26(3):203-8. doi: 10.1089/ pho.2007.2130.

36. Tuncdemir AR, Yildirim C, Ozcan E, Polat S. The effect of a diode laser and traditional irrigants on the bond strength of self-adhesive cement. J Adv Prosthodont. 2013;5(4):45763. doi: 10.4047/jap.2013.5.4.457. 